\title{
Effect of a deciduous shrub on microclimate along an elevation gradient, Mount Koma, northern Japan
}

\author{
Shiro Tsuyuzaki ${ }^{1, *}$, Miyuki Matsuda ${ }^{1,2}$, Munemitsu Akasaka ${ }^{1,3}$ \\ ${ }^{1}$ Graduate School of Environmental Earth Science, Hokkaido University, Sapporo 060-0810, Japan \\ ${ }^{2}$ Present address: IDEA Consultants Inc., 3-15-1 Komazawa, Setagaya Ward, Tokyo 154-8585, Japan \\ ${ }^{3}$ Present address: National Institute for Environmental Studies, 16-2 Onogawa, Tsukuba, Ibaragi 305-8506, Japan
}

\begin{abstract}
To detect the effects of a deciduous shrub Salix reinii on microclimate along a gradient of elevation during the snow-free period, we measured ground surface temperature and surface photosynthetically active radiation (PAR) for bare ground and $S$. reinii patches (henceforth 'patches'). Measurements were made at low (560 m above sea level), middle (665 m), and high $(755 \mathrm{~m})$ elevations on the Mount Koma volcano in northern Japan. Soil water content was also measured for bare ground and under $S$. reinii patches at the middle elevation, and wind speed was measured on bare ground at all 3 elevations. The forest canopy, dominated by Larix kaempferi, was more developed at lower elevations, and wind speeds there were lower. The PAR value in patches decreased with increasing foliage, which also reduced temperature fluctuations at all 3 elevations. The water content remained higher in patches than on bare ground. These observations show that shrub cover markedly reduces temperature fluctuation and soil desiccation by intercepting solar radiation. Differences in microclimate between the 3 elevations were less in the shrub patches, showing that the patches weakened the effects of elevation and canopy on microclimate at each of the elevations surveyed.
\end{abstract}

KEY WORDS: Microclimate · Ground-surface temperature fluctuation · Photosynthetically active radiation $\cdot$ PAR $\cdot$ Salix reinii shrub patch $\cdot$ Water content in volcanic deposits

\section{INTRODUCTION}

Microclimate influences ecosystem structures and functions, both directly and indirectly (Chen et al. 1999). For instance, in a Pseudotsuga menziesii forest, temperature and soil moisture in summer are more variable in small gaps created by fallen trees than in closed canopies (Gray et al. 2002). Through the creation of shelters, a forest canopy influences plant growth in the understory by changing temperature and wind speed (Proe et al. 2001). Canopies of Pinus flexilis trees reduce wind intensity, especially on the leeward side, and hinder the establishment of understory herbs and shrubs (Baumeister \& Callaway 2006). A larch species, Larix kaempferi, has migrated from the bottom of the Mount Koma volcano in
Hokkaido Island in northern Japan, so that the forest canopy and age gradually decrease with increasing elevation (Akasaka \& Tsuyuzaki 2009). In mixed conifer forests, fluctuations of the microclimate are influenced primarily by elevation and canopy cover (Ma et al. 2010). The effects of forest canopy on microclimate should therefore be examined at differing elevations in mountainous regions.

The shading and shelter effects of shrub patches affect the microclimate, which is characterized by temperature, light intensity, and soil moisture (Walker et al. 2003, Gomez-Aparicio et al. 2005). On Mount Koma, Salix reinii shrubs facilitate the establishment of perennial herbs by improving soil moisture, light intensity, and/or seed-trapping (Uesaka \& Tsuyuzaki 2004). S. reinii is a deciduous shrub found in central 
Japan and the southern Kurile Islands (Ohwi \& Kitagawa 1983). The effects of deciduous shrubs on microclimate differ with season as a result of leaf phenology, so that they are dynamic and complex (El-Bana et al. 2002, Baumeister \& Callaway 2006). Furthermore, there is little micrometeorological data from mid- and upper-elevational sites on mountains (Friedland et al. 2003). Seasonal changes in microclimate induced by $S$. reinii patches should therefore be determined along a gradient of elevation with increasing canopy openness. Using $S$. reinii shrub, we compared microclimate between bare ground and shrub patches during the plant-growing seasons at 3 elevations on Mount Koma. We focused on how the shrubs reduced differences in microclimate with elevation. We propose that the $S$. reinii patches moderate the microclimate at all elevations, because they facilitate the establishment of perennial herbs, even at high elevations (Uesaka \& Tsuyuzaki 2004).

\section{MATERIALS AND METHODS}

\subsection{Study area and plant materials}

Mount Koma is a stratovolcano situated in southern Hokkaido, northern Japan $\left(42^{\circ} 02^{\prime} \mathrm{N}, 140^{\circ} 40^{\prime} \mathrm{E}\right.$; $1131 \mathrm{~m}$ above sea level). In 1929, a 1 d eruption produced $0.38 \mathrm{~km}^{3}$ of ash and $0.14 \mathrm{~km}^{3}$ of pumice, and the resulting mudflow destroyed most vegetation on the slopes (Yoshii 1932). The volcanic deposits were dominated by pumice and volcanic ash. Small eruptions occurred close to the summit in 1996, 1998, and 2000, but did not affect the SW slope studied in the present study (Tsuyuzaki \& Hase 2005). Patches of Salix reinii shrub are widespread on the slopes of the volcano (Fig. 1), and leaf emergence usually begins in early May soon after snow-melt. Leaf production is complete in summer, and defoliation occurs gradually until snow-packing occurs (Uesaka \& Tsuyuzaki 2004).

In the present era, revegetation has proceeded from the bottom to the top of the mountain, mainly by the migration of the deciduous needle-leaved tree Larix kaempferi (Nishi \& Tsuyuzaki 2004). To determine the changes in forest structures along an elevational gradient, sixteen $20 \times 20 \mathrm{~m}$ plots were set up at altitudes of between 546 and 830 m elevation (Fig. 1). In these plots, the diameter at chest height $(1.3 \mathrm{~m})$ and the height of each tree were measured in 2004 and 2007. The basal area was calculated from the diameters. The tree height and basal area are surrogates for the tree canopy area, since they are

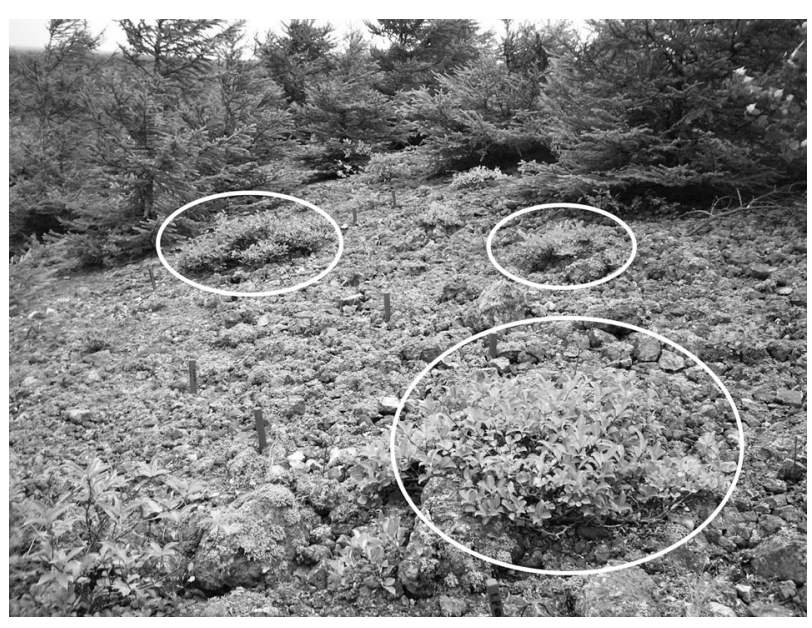

Fig. 1. Salix reinii and Larix kaempferi. S. reinii shrub patches established on the SW slope of Mount Koma (photo: 8 Sep 2005). The location is close to the low elevation site. Most areas without $S$. reinii patches were covered with pumice and ash, i.e. bare ground. Large shrub patches are encircled. L. kaempferi trees are seen in the background

positively related to the canopy area on Mount Koma (Kondo \& Tsuyuzaki 1999, Akasaka \& Tsuyuzaki 2009).

\subsection{Microclimate measurements}

Weather stations (Hobo Weather Station, Onset) were set at each of 3 elevations on the SW slope of the mountain (Fig. 1): $560 \mathrm{~m}$ (henceforth referred to as low elevation), $665 \mathrm{~m}$ (middle), and $755 \mathrm{~m}$ (high). A wind gauge (S-WCA-M003) was established $50 \mathrm{~cm}$ above the surface on bare ground at each elevation. A thermometer (S-TMA-M017) and a photosynthetically active radiation (PAR) sensor (S-LIA-M003) were established at ground level on bare ground and in a Salix reinii shrub patch (henceforth 'patch') at each elevation. The sensors were set up in the center of the patches. In addition, at the middle elevation a rain gauge (S-RGB-M006) was set up on bare ground, and a time-domain reflectometer (S-SMAM003) was placed on bare ground and in the patch at a depth of $5 \mathrm{~cm}$. Measurements took place from 1 July to 31 October 2005 and from 1 to 30 June 2006, at 10 min intervals.

Where the weather stations were set up on bare ground, vascular plants covered $<1 \%$ of the area, and mosses and lichens were established only sparsely (Fig. 1). Litter accumulation was least on bare ground. To specify the patch structures of Salix reinii, densities of leaves and branches on each patch 
were measured in mid-summer when leaf-flushing was complete. Each patch was covered by a $1 \times 1 \mathrm{~m}$ frame having one hundred $10 \times 10 \mathrm{~cm}$ square cells. A steel pin (diameter $3 \mathrm{~mm}$ ) was then moved vertically down to the ground surface at each cell intersection, and numbers of branches and leaves contacted by the pin were counted. Based on the number of counts, the mean densities of leaves and branches were calculated (total number of contacts per 121 intersections per $\mathrm{m}^{2}$ ). The thickness of the litter was also measured at each cell.

\subsection{Statistical and model analysis}

Daily mean temperature and standard deviation (SD) were calculated from the collected data. The SD was taken as a measure of the temperature fluctuation within a day. The relative intensity of PAR (henceforth, relative PAR) (\%) in the patch was calculated from the formula: (PAR on patch)/(PAR on control) $\times 100$.

As the habitat (bare ground and patch) was a categorical variable, generalized linear modeling (GLM) was used for all analyses, using the statistical program R (ver. 2.10.1) (R Foundation for Statistical Computing) with 2 libraries, MASS and lmer. The densities of leaves and branches in the patches at the 3 elevations were compared, using the numbers of leaves and branches touched at each intersection of the cells in shrub patches. The comparisons were conducted by GLM with a Poisson distribution. GLM was also used to predict the microclimate characteristics within a patch. The response variables were daily mean temperature, temperature fluctuation, and PAR. In studying temperature fluctuation, the mean temperature was added into the explanatory variable. These response variables were then compared for bare ground and patch, taking into account elevation and day length. Day length is parameterized to predict phenological changes in leaf density for deciduous plants (Arora \& Boer 2005). Interaction between day length and leaf density was therefore inserted into the model. Day length was calculated from a formula based on latitude, longitude, altitude, slope direction, and gradient (JHA 2011). Interaction between elevation and habitat was also examined. The best-fit GLMs were selected by Akaike's information criteria (AIC) (Burnham \& Anderson 2002). Wind speeds, measured by a $10 \mathrm{~min}$ average and gust, were compared across elevations by GLM with a Gaussian distribution, following square-root transformation. The difference in water content between bare ground and the patch at middle elevation was examined by GLM with a Gaussian distribution. Temperature fluctuations on bare ground and the patch were predicted by 4 GLMs, so as to extract significant relationships between microclimatic characteristics (see Table 1).

\section{RESULTS}

\subsection{Changes with elevation of tree canopy and wind}

The total basal area of trees increased with decreasing elevation (Fig. 2), and increased from 2004 to 2007, particularly at lower elevations. There were few trees at the high elevation, i.e. 6 stems with $52 \mathrm{~cm}^{2}$ basal area on the plot in 2004, and 25 stems with $199 \mathrm{~cm}^{2}$ in 2007 . The total basal area at the low elevation was $562 \mathrm{~cm}^{2}$ with 39 stems in 2004, and $871 \mathrm{~cm}^{2}$ with 49 stems in 2007 . The basal area at the middle elevation was intermediate between low and high elevations: $305 \mathrm{~cm}^{2}$ with 10 stems in 2004, and $557 \mathrm{~cm}^{2}$ with 53 stems in 2007. As well as the basal area and stem density, trees at higher elevations were not as tall. The maximum tree heights in 2004 at the low, middle, and high elevations were 5.1, 4.4, and $3.0 \mathrm{~m}$, respectively, and in 2007 were $5.6,4.8$, and $4.6 \mathrm{~m}$, respectively. These values show that the effects of trees on the microclimate at the ground surface differed between the elevations. In 2005 and 2006, when the microclimate data were recorded, the

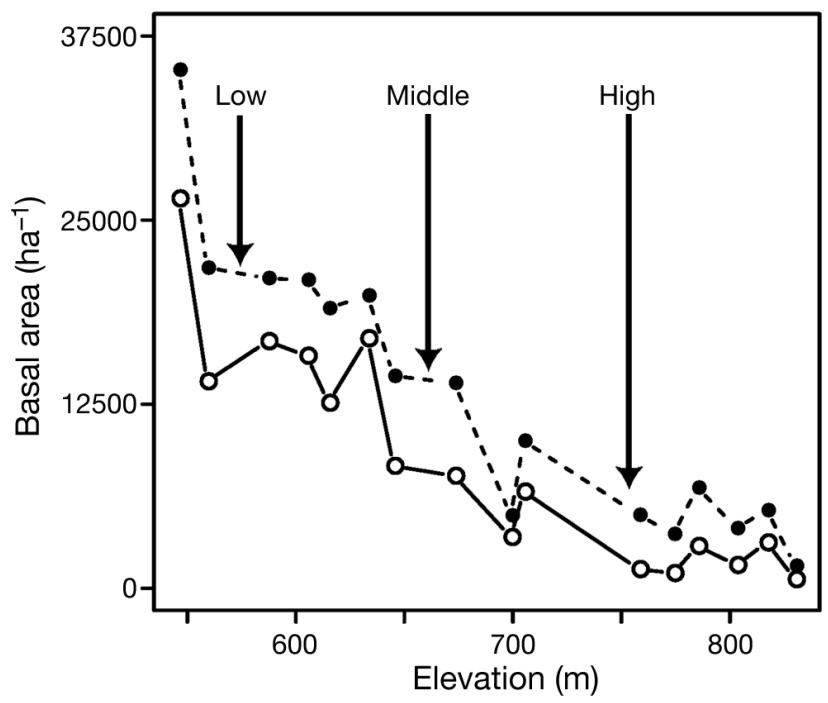

Fig. 2. Total tree basal area measured in sixteen $20 \times 20 \mathrm{~m}$ permanently marked quadrats across elevation in 2 surveyed years, $2004(0)$ and $2007(\bullet)$. The arrows correspond to the 3 sites where microclimate was measured 
tree canopy size was intermediate between the 2004 and 2007 values.

The daily wind speed averaged over $10 \mathrm{~min}$, and the peak (gust) value differed significantly between elevations (GLM, p < 0.01), and were least at lower elevations (Fig. 3). The maximum gust was 9.46, 10.95, and $14.84 \mathrm{~m} \mathrm{~s}^{-1}$ at low, middle, and high elevations, respectively.

\subsection{Shrub structure}

Salix reinii patch sizes were $0.47,0.66$, and $0.43 \mathrm{~m}^{2}$ at the low, middle, and high elevations, respectively, and the mean heights were 17, 19, and $11 \mathrm{~cm}$, respectively. Leaf density (no. of contacts per intersection; see Section 2.2) was $0.95 \pm 1.33$ (mean \pm SD) at the low, $1.71 \pm 1.40$ at the middle, and $1.15 \pm 1.27$ at the high elevation, and branch density (no. of contacts per intersection) was $0.26 \pm 0.63$ at low, $0.57 \pm$ 0.73 at middle, and $0.44 \pm 0.82$ at high elevation. The

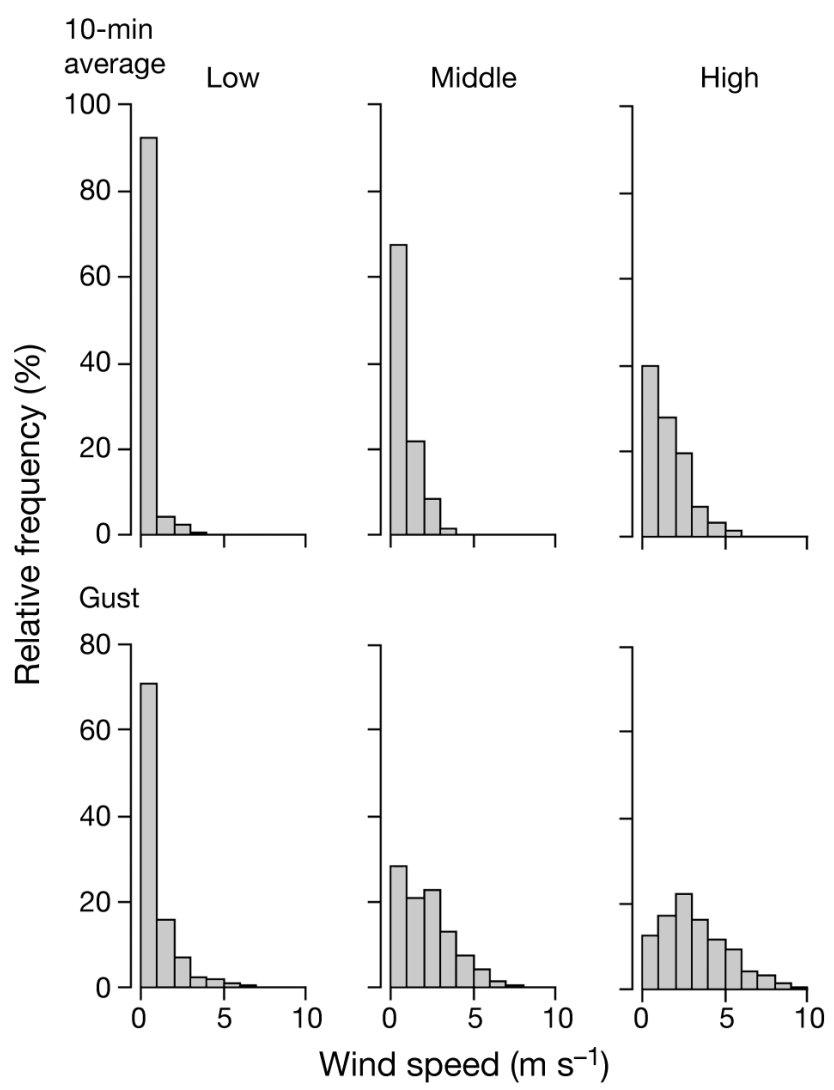

Fig. 3. Frequency distributions of wind speed expressed by the average for $10 \mathrm{~min}$ (upper panels) and gust (peak value) at a height of $50 \mathrm{~cm}$ above the ground surface (lower panels) at 3 elevations (low, middle, high) in the snow-free periods from July 2005 to June 2006. Wind intensities were less at lower elevation (GLM, significant at $\mathrm{p}<0.01)$ mean density of leaves was higher at the middle elevation than at the low and high elevations $(p<0.01)$, and that of branches did not differ between elevations $(p>0.01)$. Litter thickness was synchronized with the leaf density of shrub patches: $0.2 \pm 0.2 \mathrm{~cm}$ at low, $1.1 \pm 1.2 \mathrm{~cm}$ at middle, and $0.6 \pm 0.8 \mathrm{~cm}$ at high elevation, although the statistical significances were weak $(0.01<\mathrm{p}<0.05)$.

\subsection{Seasonal changes in foliage and PAR}

The daily mean PAR on bare ground ranged from 22.6 to $666.3 \mu \mathrm{mol} \mathrm{m}{ }^{-2} \mathrm{~s}^{-1}$, and that in a shrub patch varied from 1.3 to $255.8 \mu \mathrm{mol} \mathrm{m} \mathrm{m}^{-2} \mathrm{~s}^{-1}$ (Fig. 4). The PAR on bare ground was correlated positively with length of day ( $p<0.01)$, and was highest at high elevation where tree canopy was least $(p<0.01)$. The PAR in patch was not significantly correlated with day length. These results imply that shading by the patch is the main factor determining the PAR in patches. The PAR was significantly lower in the patch than at bare ground throughout the surveyed periods ( $\mathrm{p}<0.01)$ (Fig. 4). For PAR, interaction between elevation and habitat was significantly positive $(\mathrm{p}<0.01)$, showing that patches reduced PAR to a greater extent at higher elevations.

The relative PAR was $<30 \%$ at the 3 elevations in July and August, but at the low and middle elevations in October it was around $60 \%$ (Fig. 4). Relative PAR was negatively correlated with length of day ( $\mathrm{p}<0.01)$, i.e. low in summer, indicating that it is greatly influenced by foliage. The relative PAR decreased with increasing elevation $(p<0.01)$. In particular, the relative PAR was low at high elevation in June and October, suggesting that the timing of defoliation of Salix reinii differs between the elevations.

\subsection{Temperature changes}

The mean daily temperatures at both bare ground and shrub patches rose significantly with day length ( $p<0.01$ ) (Fig. 5). The temperatures on bare ground were highest at low elevation $(p<0.01)$, but did not differ significantly between the middle and high elevations. The mean temperature was $1.3^{\circ} \mathrm{C}$ lower on shrub patches than on bare ground throughout the snow-free period, indicating that not only leaves, but also branches, reduced the temperature. Temperatures in the patches decreased more in July and August than in June and October, implying that foliage 

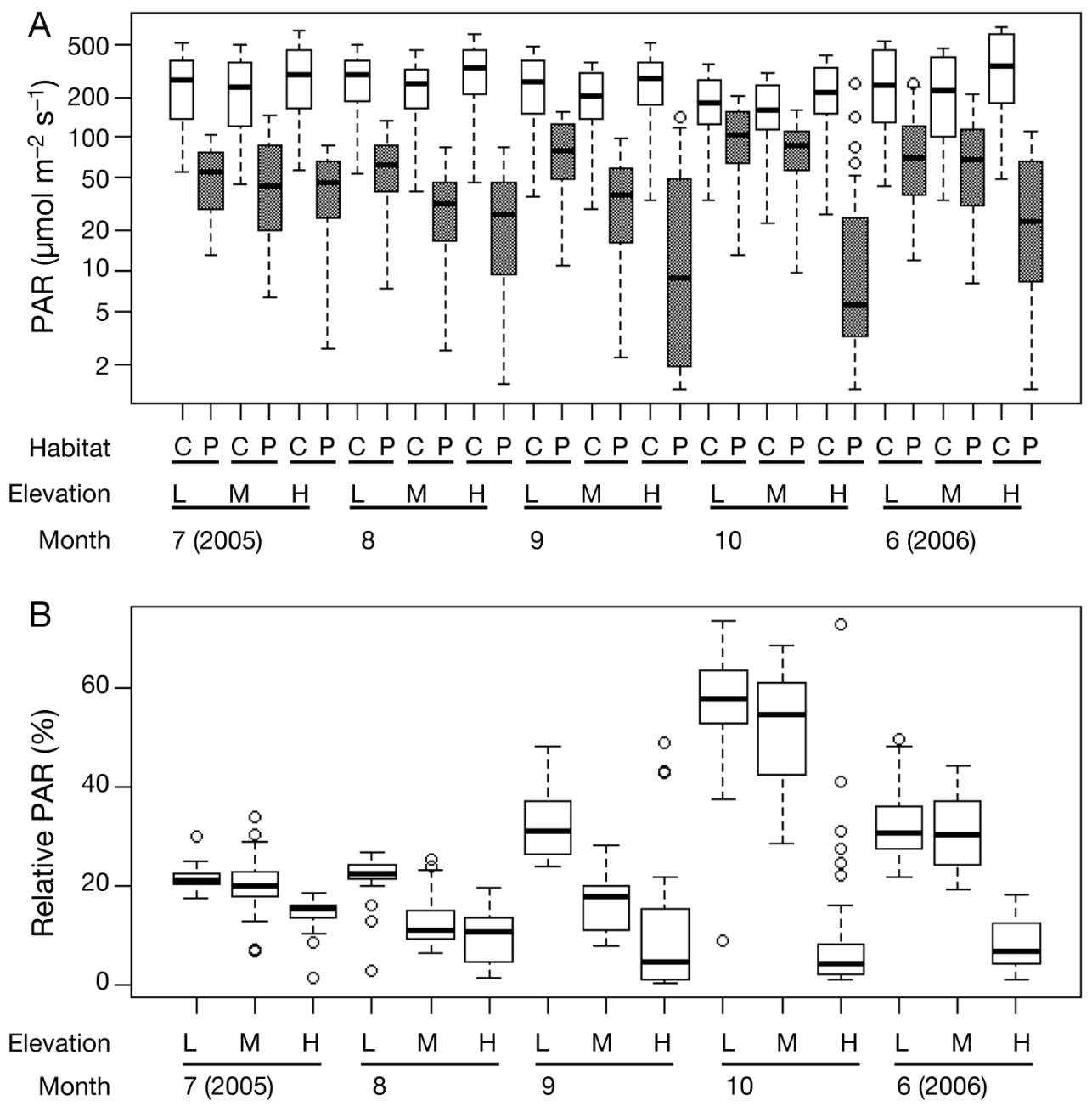

Fig. 4. Seasonal changes in photosynthetically active radiation (PAR) on bare ground and Salix reinii patches at the 3 elevations. (A) Daily mean PAR in each habitat $(\mathrm{C}=$ control, $\mathrm{P}=$ patch) at the 3 elevations $(\mathrm{L}=\operatorname{low}, \mathrm{M}=\mathrm{middle}, \mathrm{H}=\mathrm{high})$ on a log scale. (B) Relative PAR in patches expressed by (PAR in patch) / (PAR in control) $\times 100$ at the 3 elevations. The measurement years are shown in parentheses. PAR at bare ground is significantly related to day length, is highest at the high elevation, and always higher than PAR in patches (GLM, $\mathrm{p}<0.01)$. PAR in a patch increases with day length and elevation. Interactions were not significant on bare ground, and between elevations and habitats were significant and positive on patches. Lower and upper edges of boxes: 25 and $75 \%$ quartiles, respectively. Whiskers: range of maximum and minimum values (length of whiskers is 1.5 times the interquartile range). Circles: outliers

greatly reduced the temperature. With increasing elevation, the temperature in the patches became lower.

The daily temperature fluctuation, expressed by $\mathrm{SD}$, increased with increasing mean temperatures at both bare ground and patches $(p<0.01)$. The fluctuation decreased with decreasing day length. Shrub patches reduced temperature fluctuation at all elevations. The fluctuations on bare ground did not differ significantly between the 3 elevations $(p<0.01)$; fluctuations at patches were least at the middle elevation $(p<0.01)$. The leaves and branches of Salix reinii patches were densest at the middle elevation, so the shrub structures are clearly involved in reducing temperature fluctuations.

\subsection{Water content in volcanic deposits}

Water content in the volcanic deposits increased in bare ground immediately after rainfall (Fig. 6). In the absence of rainfall, water content decreased gradually with time. This trend was clearer in bare ground than in patches, so that patches support higher water content in the volcanic deposits. High water retention in the patches was clearly observed in July and August 2005, when the shrubs were fully foliated. The water content throughout was higher in the patches than in bare ground $(\mathrm{p}<0.01)$; the differences were $4.1 \%$ in July, $3.1 \%$ in August, $1.6 \%$ in September, and $1.2 \%$ in October. 

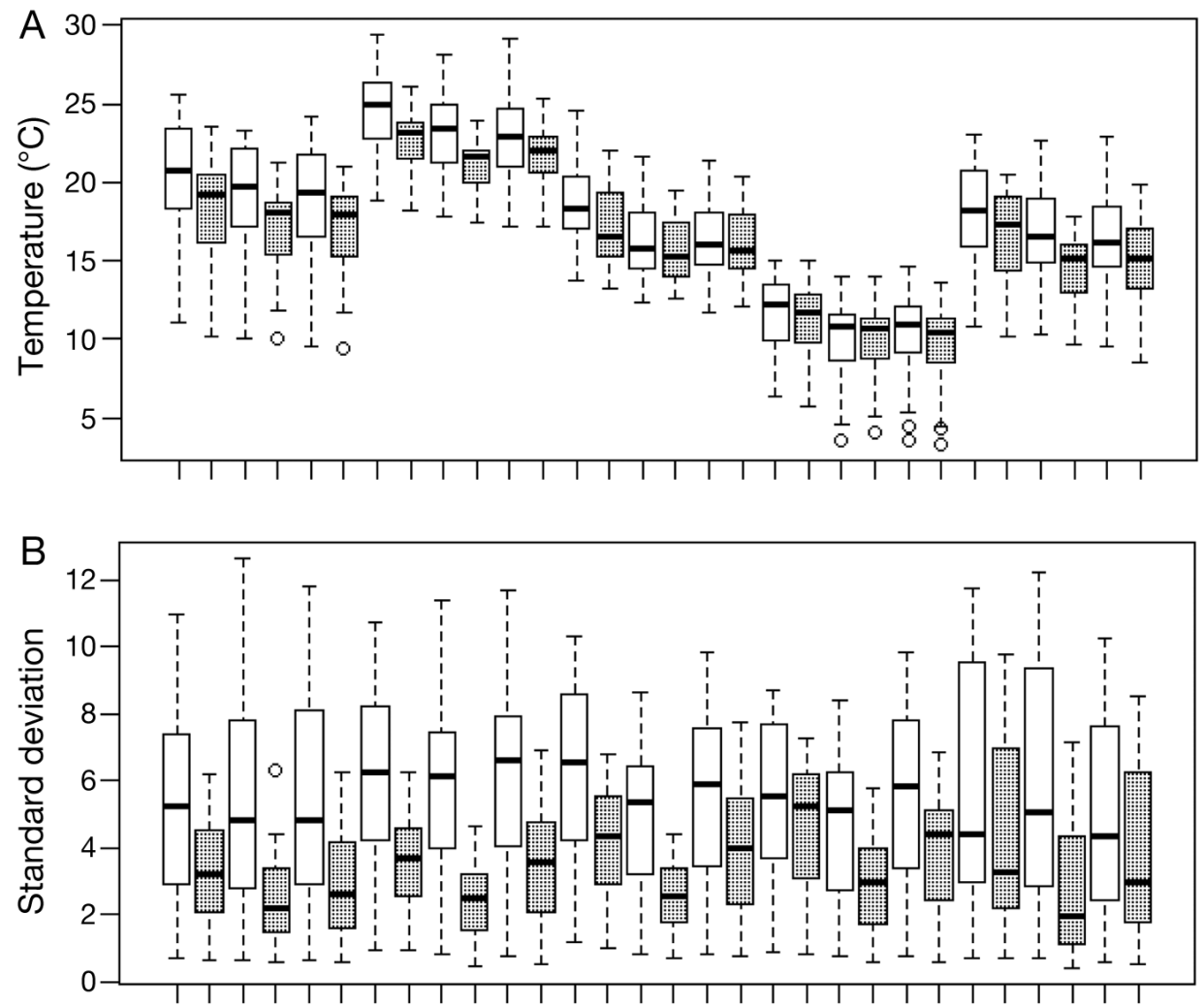

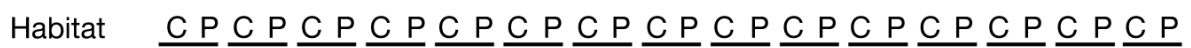

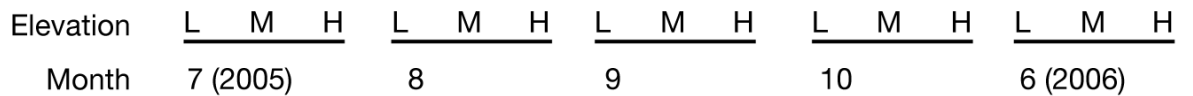

Fig. 5. Temperature fluctuations (A: daily mean, B: standard deviation) on bare ground and in patches at 3 elevations. Mean daily temperatures on both bare ground and patches were positively correlated with day length (GLM, significant at $\mathrm{p}<0.01$ ). Temperature on bare ground was highest at low elevation $(\mathrm{p}<0.01)$, but did not differ between middle and high elevations $(p>0.01)$. Mean temperature was lower on patches than on bare ground regardless of the months ( $p<0.01)$. See Fig. 4 for abbreviations and definition of graph components

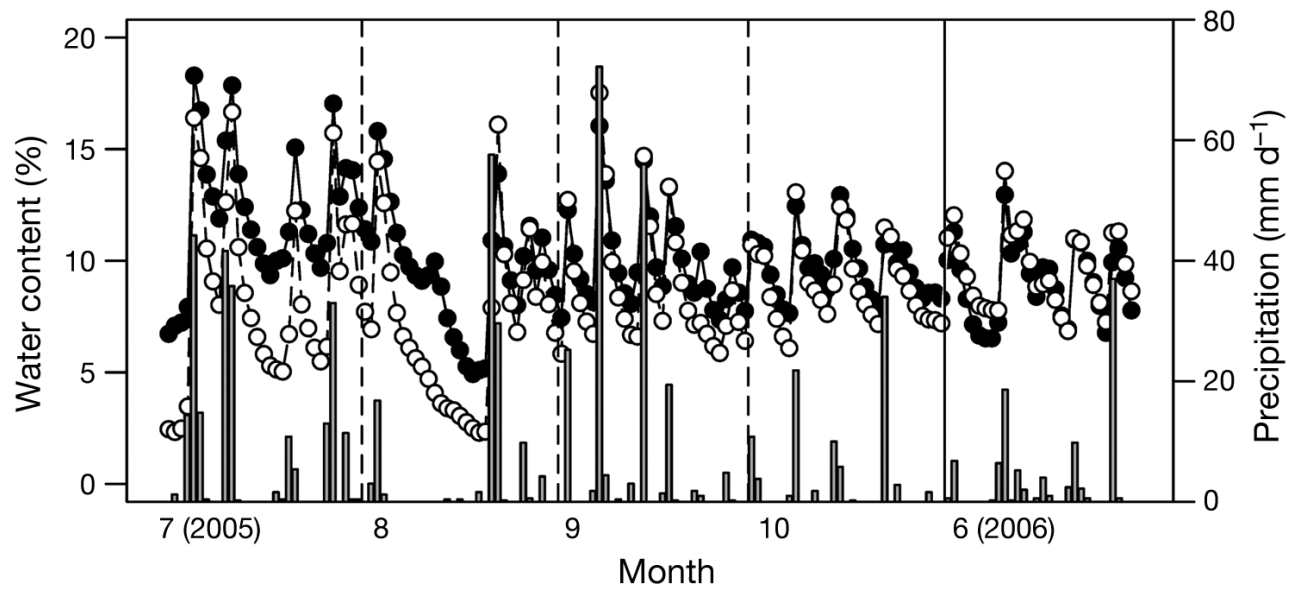

Fig. 6. Daily mean water content (- -) in volcanic deposits, and total rainfall (vertical columns) at middle elevation (665 m above sea level) on Mount Koma. Water content is shown for bare ground (0) and Salix reinii patches (๑). Dashed and solid vertical lines show the boundaries of months and years, respectively. Water content was significantly higher in patches than in bare ground (GLM, p < 0.01) 


\subsection{Temperature fluctuations within a day}

The greatest difference between minimum and maximum temperatures was $22.7^{\circ} \mathrm{C}$ at $12: 30 \mathrm{~h}$ on 30 June 2005 at the middle elevation (Fig. 7). The temperatures on that day were lower in patches than on bare ground during the daytime at each elevation. The reduction of temperature in the patch was particularly notable around midday.

Shrub patches reduced the PAR at all elevations (Fig. 7). The PAR in patches was high around sunrise and sundown, probably because the structures of leaves and branches allowed angled light penetration. The temperatures on bare ground did not differ greatly between the elevations on that day. In contrast, the temperatures in the patches differed between elevations; in particular, the temperatures were highest at the low elevation.

\subsection{Determinants of temperature fluctuation}

The temperature fluctuation on bare ground at the middle elevation was modeled by the following equation (for the abbreviations in the equations, see Table 1):

$$
\begin{aligned}
T_{b s d}= & 0.022 P_{b m n}-0.160 W_{b m n}-0.042 R-0.263 G \\
& -0.372 D+0.005\left(W_{b m n} \times G\right)-7.91
\end{aligned}
$$

Here, $P_{b m n}, W_{b m n}, G, D$, and the intercept were significant at $\mathrm{p}<0.01 . T_{b s d}$ decreased with increasing $W_{b m n}, R$, and $G$. The interaction between $W_{b m n}$ and $G$ was also significant, showing that wind (indicated by gust) and water content jointly influenced the temperature fluctuation. The fluctuations were smaller for a shorter length of day.

The temperature fluctuation in patches at the middle elevation was modeled by the following equation:

$$
\begin{aligned}
T_{p s d}= & 0.373 T_{b s d}+0.016 P_{p m n} \\
& -0.003 P_{p s d}+0.034 W_{p m n} \\
& +0.005 R+0.037 G \\
& -0.104 D+0.870
\end{aligned}
$$

Here, $T_{b s d}, P_{p m n}$, and $D$ were significantly correlated with $T_{p s d}$ at $\mathrm{p}<0.01$. The mean temperature on bare ground was eliminated from the model, indicating that the temperature fluctuation in a patch did not depend on it. The intercept was significant at $\mathrm{p}<0.01$. The interaction between water content in the patch and precipitation was discarded in the model. The highest $t$-value in the model was for the temperature fluctuation on bare ground $\left(T_{b s d}\right)$, indicating that $T_{b s d}$ was the most significant determinant of temperature fluctuation on a patch $\left(T_{p s d}\right)$ and was related strongly to fluctuation on bare ground. The correlation coefficient between $T_{b s d}$ and $T_{p s d}$ was high, at +0.888 $(p<0.01)$. Furthermore, the correlation coefficient between the observed and predicted temperature fluctuations in Eq. (2) became higher, i.e. +0.952. Eq. (2), comprising 7 explanatory variables, shows that the selected microclimatic factors also regulate tem-

perature fluctuation.
Fig. 7. Microclimatic changes in (A) temperature and (B) photosynthetically active radiation (PAR) during the day for which the difference in temperature between bare ground and patch was greatest, on 30 June 2005. Low $(O)$, middle $(\Delta)$, and high $(\diamond)$ elevations are included. Open symbols indicate bare ground (as control) and closed symbols refer to Salix reinii patches 
Table 1. Four primary models for studying the determinants of temperature fluctuation were constructed, and the final best models chosen by significant explanatory variables, based on stepwise AIC procedures. $T_{b s d}$ and $T_{p s d}=$ daily temperature fluctuation at middle elevation expressed by SD in bare ground and patch, respectively. $F_{b s d}$ and $F_{p s d}=$ temperature fluctuation at all elevations in bare ground and patch, respectively. $T_{b m n}=$ daily mean temperature in bare ground. $P_{b m n}$ and $P_{b s d}=$ daily mean and SD, respectively, of PAR in bare ground. $P_{p m n}$ and $P_{p s d}=$ daily mean and SD, respectively, of PAR in patch. $W_{b m n}$ and $W_{p m n}=$ daily mean water content in bare ground and patch, respectively. $R=$ precipitation. $G=$ gust. $D=$ day length. $E=$ elevation. $L=$ leaf density on shrub patch. $B=$ branch density on patch. $L_{t}=$ litter thickness. The symbol $(\times)$ indicates interaction, $\alpha_{i}$ is the slope of each explanatory variable in the equation, and $\beta$ is the intercept. The delayed effect of PAR on temperature is not considered, because a preliminary analysis showed no time-lag between PAR and temperature at 10 min intervals. Wind speed was not used in the model to remove the autocorrelation, because the gust was highly auto-correlated to the averaged wind speed and was a better predictor in the models

\begin{tabular}{|lll|}
\hline \multirow{2}{*}{ Model } & \multicolumn{2}{c}{ Variable } \\
& Dependent Explanatory \\
\hline 1 & $T_{b s d}=$ & $\alpha_{1} \cdot P_{b m n}+\alpha_{2} \cdot P_{b s d}+\alpha_{3} \cdot W_{b m n}+\alpha_{4} \cdot R+\alpha_{5} \cdot G+\alpha_{6} \cdot D+\alpha_{7} \cdot\left(W_{b} \times R\right)+\beta$ \\
2 & $T_{p s d}=$ & $\alpha_{1} \cdot T_{b m n}+\alpha_{2} \cdot T_{b s d}+\alpha_{3} \cdot P_{b m n}+\alpha_{4} \cdot P_{b s d}+\alpha_{5} \cdot P_{p m n}+\alpha_{6} \cdot P_{p s d}+\alpha_{7} \cdot W_{p m n}+\alpha_{8} \cdot R+\alpha_{9} \cdot G+\alpha_{10} \cdot D+\alpha_{11} \cdot\left(W_{p m n} \times R\right)+\beta$ \\
3 & $F_{b s d}=$ & $\alpha_{1} \cdot P_{b m n}+\alpha_{2} \cdot P_{b s d}+\alpha_{3} \cdot G+\alpha_{4} \cdot D+\alpha_{5} \cdot E+\beta$ \\
4 & $F_{p s d}=$ & $\alpha_{1} \cdot T_{b s d}+\alpha_{1} \cdot P_{b m n}+\alpha_{2} \cdot P_{b s d}+\alpha_{3} \cdot G+\alpha_{4} \cdot D+\alpha_{5} \cdot E+\alpha_{6} \cdot L+\alpha_{7} \cdot B+\alpha_{8} \cdot L_{t}+\alpha_{9} \cdot(L \times D)+\beta$
\end{tabular}

The temperature fluctuations on bare ground at the 3 elevations were modeled by the following equation:

$$
\begin{aligned}
F_{b s d}= & 0.006 P_{b m n}+0.010 P_{b s d}-0.260 G-0.340 D \\
& +0.001 E+5.540
\end{aligned}
$$

Of the explanatory variables examined, only water content was not adopted in this model. Temperature fluctuations on bare ground were positively related with mean daily PAR on both bare ground and patches, and with elevation, but negatively correlated with precipitation, gust, and day length.

The temperature fluctuations in patches at the 3 elevations were modeled by the following equation:

$$
\begin{aligned}
F_{p s d}= & 0.011 P_{b m n}-0.099 G-3.362 L-2.195 B \\
& -0.755 D+0.240(L \times D)+12.235
\end{aligned}
$$

Elevation was not adopted in Eq. (4) for predicting temperature fluctuation in shrub patches, but it was involved in the Eq. (3) for the fluctuation on bare ground. These results imply that the effects of a patch on temperature fluctuation do not depend on elevation and are due to plant structures, represented by the densities of leaves and branches.

\section{DISCUSSION}

\subsection{Effects of tree canopy and elevation on microclimate}

Wind speed was less at lower elevations with more tree canopy. Since tree height and density decreased with increasing elevation, the wind speed was greater with the combined effects of elevation and tree canopy. Forest gaps created by timber harvest- ing raise wind speed by $40 \%$ in upland forests in the UK (Proe et al. 2001). Microclimate and facilitation are essential for tree regeneration, which is necessary for the treeline to move upwards (Richardson \& Friedland 2009). Furthermore, the PAR on bare ground increased with increasing elevation, where the tree canopy decreased. PAR greatly influenced mean temperature and temperature fluctuation on bare ground. Shading by the tree canopy influences temperature fluctuations more strongly on hotter days during summer (Renaud \& Rebetez 2009).

These observations suggest that the effects of the forest canopy increase with increasing succession on volcanoes. As the dominant tree, Larix kaempferi, migrates on Mount Koma from the foot to the SW slope, tree age is positively correlated with elevation (Kondo \& Tsuyuzaki 1999). The tree canopy will increasingly affect the microclimate more in the future, even at high elevation.

\subsection{Shrub patch effects on above-ground microclimate}

Salix reinii shrub patches greatly reduced mean daily temperature and PAR, particularly in summer when leaf density was high. In Mediterranean shrubland, shading by shrub leaves reduces photoinhibition and water stress during the humid spring and dry summer (Cuesta et al. 2010). Although the larch is also deciduous, PAR did not vary greatly on bare ground with changing day length. These findings suggest that the changes in microclimate were due more to $S$. reinii shrub patches than Larix kaempferi tree canopies. 
The wind speed should be reduced under the patch shelters, particularly when foliage is well developed in summer (although the wind speed was not measured in the patches). Most litter was accumulated in the patches, and its thickness was positively correlated with leaf density. Litter accumulates more under larger shrub patches, because wind speeds are lower (El-Bana et al. 2002). Dwarf shrub structure, including Salix reinii, appears to capture more litter than a bare ground surface. Levels of nutrients originating from litter in the volcanic deposits subsequently become higher in the patches than in bare ground (Zhao et al. 2007, Endo et al. 2008). Litter mulch also reduces frost damage to seedlings in early spring and late fall (Groeneveld \& Rochefort 2005).

\subsection{Shrub patch effects on below-ground microclimate}

Both the above-ground microclimate and belowground microclimate were moderated by shading. Water content remained higher and fluctuated less in the patches than in bare ground, indicating that the patches influenced the below-ground microclimate also. Since the texture of volcanic deposits did not differ between bare ground and shrub patches (Uesaka \& Tsuyuzaki 2004), the high water content in patches must be due mainly to shading by the leaves and branches of shrubs. Patches of Caragana microphylla and Salix gordejevii shrubs increase moisture in soils and act as seed traps in Mongolian sand dunes (Zhao et al. 2007). Shrub patches are more helpful for the establishment of seedlings on dry soil than on wet soil in a Mediterranean montane shrubland, through the maintenance of high soil moisture (Gomez-Aparicio et al. 2005). The high water content of soil in shrub patches promotes seedling survival in xeric habitats (Plamboeck et al. 2008).

The soil moisture beneath shrubs is different for different shrub species (Cavieres et al. 2007). A nitrogen-fixing Alnus viridis thicket $3 \mathrm{~m}$ in height was found to reduce water content in volcanic deposits during summer on the pumice plains of Mount St. Helens, probably because of water uptake by $A$. viridis (Titus 2009). The water content in the Salix reinii patch remained high, so that water-uptake and evapotranspiration in the patch did not exceed the water supply from rainfall. The amount of water retained beneath a shrub patch was particularly high when foliage was well developed, suggesting that the activity of shrubs strongly influences the belowground micro-environment.

\subsection{Seasonal changes in the effects of shrub patches}

The effects of shrub patches on microclimate changed seasonally and were greatest in summer, suggesting that foliage controls the microclimate. The evergreen shrub Gaultheria miqueliana does not facilitate the establishment of cohabitants on Mount Koma, due to continuous shading (Uesaka \& Tsuyuzaki 2004). Seasonal fluctuations in PAR are less beneath evergreen tree crowns than under deciduous tree crowns (Clinton 2003). A high PAR prior to leaf development promotes seed germination under deciduous shrubs, such as Salix reinii (Soliveres et al. 2010). On Mount Koma, most seedlings emerged before July, when leaf development was not completed (Tsuyuzaki \& Hase 2005). It follows that deciduous shrub patches have a positive effect on interspecific relationships, i.e. facilitation. S. reinii shrub patches facilitate the establishment of other species, whereas G. miqueliana inhibits them (Uesaka \& Tsuyuzaki 2004). Leaf density and day length were strongly related to temperature fluctuations in a patch. When the densities of leaves and branches were low in patches, the effects of patches on temperature fluctuation remained significant. These findings suggest that branches of shrubs also contributed to changes in the microclimate.

In conclusion, the structure and phenology of shrubs, measured by leaf and branch densities, are very important for microclimatic changes, influencing it via above-ground and below-ground mechanisms. The structure and development of shrub patches should be further studied to improve our understanding of the effects of shrubs on microclimate and facilitation.

Acknowledgements. We thank S. Uesaka, H. Nishi, and all members of the Plant Ecology Lab, Graduate School of Environmental Earth Science, Hokkaido University, for their assistance. This work is supported in part by grants from the Japan Society for the Promotion of Science.

\section{LITERATURE CITED}

Akasaka M, Tsuyuzaki S (2009) Comparisons of recruitment, survival and growth in invasive and native tree saplings on a volcano. Plant Ecol 202:235-245

Arora VK, Boer GJ (2005) A parameterization of leaf phenology for the terrestrial ecosystem component of climate models. Glob Change Biol 11:39-59

Baumeister D, Callaway RM (2006) Facilitation by Pinus flexilis during succession: a hierarchy of mechanisms benefits other plant species. Ecology 87:1816-1830

Burnham KP, Anderson DR (2002) Model selection and 
multimodel inference: a practical information-theoretic approach, 2nd edn. Springer, New York, NY

> Cavieres LA, Badano EI, Sierra-Almeida A, Molina-Montenegro MA (2007) Microclimatic modifications of cushion plants and their consequences for seedling survival of native and non-native herbaceous species in the High Andes of Central Chile. Arct Antarct Alp Res 39:229-236

> Chen J, Saunders SC, Crow TR, Naiman RJ and others (1999) Microclimate in forest ecosystem and landscape ecology. BioScience 49:288-297

Clinton BD (2003) Light, temperature, and soil moisture responses to elevation, evergreen understory, and small canopy gaps in the southern Appalachians. For Ecol Manag 186:243-255

> Cuesta B, Villar-Salvador P, Puertolas J, Benayas JMR, Michalet R (2010) Facilitation of Quercus ilex in Mediterranean shrubland is explained by both direct and indirect interactions mediated by herbs. J Ecol 98: 687-696

> El-Bana MI, Nijs I, Kockelbergh F (2002) Microenvironmental and vegetational heterogeneity induced by phytogenic nebkhas in an arid coastal ecosystem. Plant Soil 247:283-293

Endo M, Yamamura Y, Tanaka A, Nakano T, Yasuda T (2008) Nurse-plant effects of a dwarf shrub on the establishment of tree seedlings in a volcanic desert on Mt. Fuji, central Japan. Arct Antarct Alp Res 40:335-342

Friedland AJ, Boyce RL, Vostral CB, Herrick GT (2003) Winter and early spring microclimate within a mid-elevation conifer forest canopy. Agric For Meteorol 115:195-200

Gómez-Aparicio L, Gomez JM, Zamora R, Boettinger JL (2005) Canopy vs. soil effects of shrubs facilitating tree seedlings in Mediterranean montane ecosystems. J Veg Sci 16:191-198

Gray NA, Spies TA, Easter MJ (2002) Microclimatic and soil moisture responses to gap formation in coastal Douglasfir forests. Can J Res 32:332-343

Groeneveld EVG, Rochefort L (2005) Polytrichum strictum as a solution to frost heaving in disturbed ecosystems: a case study with milled peatlands. Restor Ecol 13:74-82

JHA (Japan Hydrographic Association) (2011) Table of sunrise and sundown B (digital version). Japan Nautical Chart, Tokyo

Kondo T, Tsuyuzaki S (1999) Natural regeneration patterns of the introduced larch, Larix kaempferi (Pinaceae), on the volcano Mount Koma, northern Japan. Divers Distrib $5: 223-233$

Editorial responsibility: Helmut Mayer, Freiburg, Germany
Ma S, Concilio A, Oakley B, North M, Chen J (2010) Spatial variability in microclimate in a mixed-conifer forest before and after thinning and burning treatments. For Ecol Manag 259:904-915

Nishi H, Tsuyuzaki S (2004) Seed dispersal and seedling establishment of Rhus trichocarpa promoted by a crow (Corvus macrorhynchos) on a volcano in Japan. Ecography 27:311-322

Ohwi J, Kitagawa M (1983) New flora of Japan. Shibundo, Tokyo

Plamboeck AH, North M, Dawson TE (2008) Conifer seedling survival under closed canopy and manzanita patches in the Sierra Nevada. Madrono 55:191-201

> Proe MF, Griffiths JH, McKay HM (2001) Effect of wholetree harvesting on microclimate during establishment of second rotation forestry. Agric For Meteorol 110:141-154

> Renaud V, Rebetez M (2009) Comparison between open-site and below-canopy climatic conditions in Switzerland during the exceptionally hot summer of 2003. Agric For Meteorol 149:873-880

Richardson AD, Friedland AJ (2009) A review of the theories to explain arctic and alpine treelines around the world. J Sustain For 28:218-242

Soliveres S, DeSoto L, Maestre FT, Olano JM (2010) Spatiotemporal heterogeneity in abiotic factors modulate multiple ontogenetic shifts between competition and facilitation. Perspect Plant Ecol Evol Syst 12:227-234

> Titus JH (2009) Nitrogen-fixers Alnus and Lupinus influence soil characteristics but not colonization by later successional species in primary succession on Mount St. Helens. Plant Ecol 203:289-301

> Tsuyuzaki S, Hase A (2005) Plant community dynamics on the volcano Mount Koma, northern Japan, after the 1996 eruption. Folia Geobot 40:319-330

Uesaka S, Tsuyuzaki S (2004) Differential establishment and survival of species in deciduous and evergreen shrub patches and on bare ground, Mt. Koma, Hokkaido, Japan. Plant Ecol 175:165-177

Walker LR, Clarkson BD, Silvester WB, Clarkson BR (2003) Colonization dynamics and facilitative impacts of a nitrogen-fixing shrub in primary succession. J Veg Sci 14: $277-290$

Yoshii Y (1932) Revegetation of Volcano Komagatake after the great eruption in 1929. Bot Mag Tokyo 46:208-215

Zhao HL, Zhou RL, Su YZ, Zhang H, Zhao LY, Drake S (2007) Shrub facilitation of desert land restoration in the Horqin Sand Land of Inner Mongolia. Ecol Eng 31:1-8

Submitted: January 25, 2011; Accepted: August 29, 2011 Proofs received from author(s): December 28, 2011 